\title{
TEMPESTIVIDADE DA INFORMAÇÃO CONTÁBIL EM EMPRESAS FAMILIARES BRASILEIRAS
}

\author{
The timeliness of accounting information in Brazilian family businesses \\ Tempestividad de la información contable en empresas familiares brasileñas
}

\section{RESUMO}

O objetivo do estudo foi analisar a tempestividade da informação contábil em empresas familiares brasileiras. Realizou-se uma pesquisa descritiva, documental e quantitativa. A amostra foi composta por 124 empresas, no período de 2010 a 2013. Os resultados apontaram que o lucro por ação, o tamanho da empresa e o crescimento das vendas foram variáveis significativas para explicar o retorno das ações. Em relação à tempestividade, observou-se que as informações contábeis são menos tempestivas nas empresas familiares quando considerado um horizonte de longo prazo para o retorno das ações (15 meses). Quando utilizados retornos de curto prazo (3 e 6 meses), as variáveis contábeis não se mostraram significativas, não sendo possível afirmar que as empresas familiares apresentam informações mais ou menos tempestivas. A originalidade deste estudo reside no fato de se investigar o efeito da gestão/controle familiar sobre a tempestividade das informações contábeis, tema ainda não observado no cenário brasileiro e que aborda a qualidade da informação contábil das empresas familiares sob um aspecto distinto de outros estudos, que utilizaram o conservadorismo contábil e o gerenciamento de resultados.

PALAVRAS-CHAVE | Propriedade familiar, qualidade da informação contábil, tempestividade da informação, controle familiar, gestão familiar.

\section{ABSTRACT}

The aim of this study was to analyze the timeliness of accounting information in Brazilian family businesses, and we chose a descriptive, documentary and quantitative research method for this purpose. The sample consisted of 124 companies, covering a period from 2010 to 2013. The results showed that earnings per share, overall company size and sales growth were significant variables in explaining returns on share price. In terms of timeliness, it was noted that accounting information was less timely in the case of family businesses when considering a long-term view of the return on share price (15 months). When a short-term view was considered (3 and 6 months), the accounting variables were not found to be significant, and it was not possible to confirm if family businesses had more or less timely information. The originality of this study lies in the fact that it investigates the effect of family management/control over the timeliness of financial reporting. This theme has not previously been investigated within the Brazilian scenario, and it addresses the quality of the accounting information of family businesses from a different perspective to that of other studies, which have opted to use accounting conservatism and earnings management.

KEYWORDS / Family owned, quality of accounting information, timeliness of information, family control, family management.

\section{RESUMEN}

El objetivo del estudio fue analizar la tempestividad de la información contable en empresas familiares brasileñas. Se realizó una investigación descriptiva, documental y cuantitativa. La muestra fue compuesta por 124 empresas, en el período de 2010 a 2013. Los resultados señalaron que el lucro por acción, el tamaño de la empresa y el crecimiento de las ventas fueron variables significativas para explicar el rendimiento de las acciones. En relación a la tempestividad, se observó que las informaciones contables son menos tempestivas en las empresas familiares cuando se considera un horizonte a largo plazo para el rendimiento de las acciones (15 meses). Cuando se utilizan rendimientos a corto plazo (3 y 6 meses), las variables contables no se mostraron significativas, y no fue posible afirmar que las empresas familiares presentan informaciones más o menos tempestivas. La originalidad del presente estudio reside en el hecho de investigar el efecto de la gestión/control familiar sobre la tempestividad de las informaciones contables, tema todavía no observado en el escenario brasileño y que aborda la calidad de la información contable de las empresas familiares bajo un aspecto distinto de otros estudios, que utilizaron el conservadorismo contable y la gestión de resultados.

PALABRAS CLAVE I Propiedad familiar, calidad de la información contable, tempestividad de la información, control familiar, gestión familiar. 


\section{INTRODUÇÃO}

Boa parte das empresas, ao iniciar suas atividades, é gerida por famílias, as quais podem decidir por manter a propriedade e a gestão familiar, desde que os benefícios sejam maiores do que os custos (Cheng, 2014). A propriedade familiar, nos últimos anos, tem sido objeto de inúmeras pesquisas (Miralles-Marcelo, Miralles-Quirós, \& Lisboa, 2014), com o intuito de verificar o efeito do controle e/ou gestão familiar nas empresas, sob a perspectiva da gestão e finanças empresariais (Barontini \& Caprio, 2006).

A concentração de propriedade, típica de empresas familiares, além de contribuir para a gestão e finanças empresariais, influencia de maneira positiva a qualidade da informação contábil (Alves, 2012; Cascino, Pugliese, Mussolino, \& Sansone, 2010). Nesse sentido, Wang (2006) destaca que empresas familiares fornecem informações de qualidade aos usuários das demonstrações financeiras, a fim de obterem capital ao menor custo.

Entre as diversas medidas para avaliar a qualidade da informação contábil, a tempestividade relaciona-se à perspectiva de a informação estar disponível em tempo hábil aos gestores para a tomada de decisão, de acordo com a necessidade destes. A eficácia do sistema contábil depende desse aspecto da qualidade, pois proporciona informações úteis e tempestivas para permitir a obtenção de benefícios aos gestores (Silva \& Brito, 2002). 0 Conselho Federal de Contabilidade, na Resolução nํㅜ 785 (1995), define que uma informação é tempestiva quando é divulgada em tempo hábil para que os usuários possam utilizá-la para seus fins. Além disso, a tempestividade, para Soltani (2002), é uma característica importante da informação contábil para profissionais contábeis, usuários e agências reguladoras.

Diversos estudos têm analisado a qualidade da informação contábil sob a perspectiva da tempestividade da informação, seja relacionando-a a padrões de governança (Lopes, 2009); aos ambientes competitivos (Almeida, 2010); à auditoria (Silva, Ayub, Pacheco, \& Macedo, 2012); ou à adoção dos International Financial Reporting Standards (Silva, 2013).

Sob outra perspectiva, alguns estudos têm investigado o efeito do controle/gestão familiar sobre a qualidade da informação contábil, como Cascino et al. (2010), que investigaram se a propriedade familiar em empresas italianas afetava a qualidade de relatórios financeiros, em termos de qualidade dos accruals, persistência, previsibilidade, suavização de resultados, relevância da informação e conservadorismo e tempestividade; Moura, Franz, e Cunha (2013), que analisaram se empresas familiares com níveis diferenciados de governança corporativa apresentavam melhor qualidade da informação contábil, em termos de persistência dos resultados e dos fluxos de caixa, oportunidade e relevância; ou Santana e Klann (2016), que avaliaram o efeito da adoção das IFRS no nível de conservadorismo de empresas familiares e não familiares.

Os estudos supracitados destacam que empresas familiares estão mais propensas a apresentar informações contábeis de qualidade superior em relação às demais, embora nenhum deles tenha investigado o efeito do controle/gestão familiar sobre a tempestividade das informações contábeis, com exceção de Cascino et al. (2010), que avaliaram tal aspecto, mas cujos resultados não foram significativos.

Quando se analisa a qualidade da informação contábil por meio da tempestividade, procura-se capturar um aspecto externo da qualidade da informação contábil, diferentemente de quando se avalia o conservadorismo ou o gerenciamento de resultados. 0 foco nesses dois últimos está dentro da empresa, pois as práticas conservadoras ou de gerenciamento ocorrem no ambiente interno à empresa. Já na tempestividade, o foco é externo, na reação dos investidores (com reflexo no preço dos títulos) às informações contábeis divulgadas. Assim, este estudo explora uma característica qualitativa da informação contábil de empresas familiares sob outro prisma, relacionado à velocidade com que a informação contábil é divulgada ao mercado por empresas de controle/gestão familiar. Assim, pressupõe-se que, dependendo do interesse dos proprietários/controladores (família), a divulgação das informações contábeis de empresas familiares poderá ser mais ou menos tempestiva.

Nesse contexto de propriedade familiar e qualidade da informação contábil sob a perspectiva de tempestividade da informação contábil, a problemática do presente estudo rege-se pela seguinte questão: qual é a tempestividade da informação contábil em empresas familiares brasileiras? Para a resolução desse problema de pesquisa, tem-se como objetivo analisar a referida tempestividade em empresas familiares brasileiras

0 presente estudo supre a lacuna de investigar o efeito do controle/gestão familiar na tempestividade da informação contábil de empresas brasileiras, visto que os demais estudos analisaram a qualidade da informação contábil sob a perspectiva da tempestividade de informações, porém não verificaram no âmbito específico de empresas familiares (Almeida, 2010; Lopes, 2009; Silva, 2013; Silva et al., 2012); ou analisaram a influência da propriedade familiar na qualidade da informação contábil sob a perspectiva de outras métricas, como o conservadorismo, gerenciamento de resultados, valor relevante, mas não sob o enfoque da tempestividade da informação (Cascino et al., 2010; Moura et al., 2013).

Dessa forma, torna-se oportuno investigar, no cenário de empresas brasileiras, em que medida as informações contábeis são tempestivas para empresas familiares, comparando-se com 
as não familiares. Ao considerar que empresas familiares operam suas atividades com foco no longo prazo, primando mais por sua continuidade no mercado e não tanto com foco no lucro imediato, como empresas não familiares, também há uma perspectiva de que as suas informações contábeis sejam mais tempestivas.

A tempestividade da informação contábil pode exercer influência para a gestão, uma vez que retornos tempestivos implicam informações mais úteis no momento da tomada de decisão aos usuários, podendo as informações disponíveis representar "boas notícias", por meio de retornos positivos, ou, ainda, "más notícias”, por meio de retornos negativos (Cascino et al., 2010). Wang (2006) destaca que as empresas familiares são mais propensas a informar o mercado sobre a magnitude de más notícias, apresentam melhor qualidade nos retornos e divulgam mais os lucros. Bushman, Chen, Engel, e Smith (2004) também ressaltam que informações tempestivas são capazes de influenciar as decisões de agentes econômicos, que, consequentemente, podem afetar o valor das ações. De acordo com Chen, Hsu, e Chen (2014), as empresas familiares possuem diferentes visões e estratégias em comparação com as demais empresas, devido ao envolvimento direto da família nas tomadas de decisões empresariais. Dessa forma, torna-se necessária a consecução de resultados empíricos sobre a qualidade da informação contábil nessas empresas, sob a perspectiva da tempestividade da informação, a fim de contribuir com as investigações já realizadas sobre as propriedades positivas ou negativas de tal controle e gestão à empresa.

\section{REFERENCIAL TEÓRICO}

Nesta seção, apresentam-se as principais referências acerca da propriedade familiar, tempestividade da informação contábil e a relação entre tempestividade da informação contábil e empresas familiares, a fim de dar embasamento teórico ao presente estudo.

\section{Empresas familiares e as informações contábeis}

As empresas familiares são o tipo de organização empresarial que predomina em todo o mundo e contribuem significativamente para a criação da riqueza mundial. A maioria das organizações é controlada por fundadores, herdeiros ou famílias dos herdeiros (Burkart, Panunzi, \& Shleifer, 2003). Há diferentes perspectivas para que uma empresa se configure como familiar. Anderson e Reeb (2003) apontam que uma empresa é familiar quando existem membros presentes no conselho de administração ou a família fundadora tem participação no capital da organização. Segundo Miller, Breton-Miller, Lester, e Canella (2007), a empresa caracteriza-se como familiar se diversos membros de uma mesma família são gerentes do negócio ou grandes proprietários.

De acordo com Donnelley (1967), este tipo de empresa deve estar relacionada a uma família e que há, no mínimo, duas gerações vem exercendo influência sobre os interesses empresariais e da família. Bornholdt (2005) define empresa familiar como aquela em que uma família ou grupos familiares detêm relevante participação acionária, todavia a gestão da empresa não necessita ser realizada por membros familiares. De modo geral, são entidades com comando na organização e administração de membros familiares.

Para Miralles-Marcelo et al. (2014), empresa familiar configura-se pela criação de uma empresa com controle de uma mesma família, mesmo quando aberto o capital. Além disso, membros da família devem estar presentes no conselho de administração ou em cargos que controlam as decisões desse conselho, bem como a cultura da família deve estar disseminada na organização. Cheng (2014) corrobora essa definição argumentando que, quando os fundadores ou descendentes da família fundadora continuam a exercer cargos importantes na administração, como no conselho, configura-se a empresa como familiar.

No atual mercado competitivo, para que uma empresa familiar se mantenha atuante, os membros familiares devem apresentar sinergia e envolvimento com a empresa. A família deve criar valor para a empresa, e a empresa deve demonstrar resultados positivos para criar valor à família (Chua, Christman, \& Steier, 2003). Fundadores de empresas que são membros de uma mesma família procuram manter a concentração de propriedade, visto que o lucro da empresa é que gera bem-estar a eles. Também nomeiam outros membros da família para realizarem atividades na gestão da empresa (Cheng, 2014).

Empresas familiares diferem das demais empresas, principalmente, pela característica de perpetuidade do negócio, tanto no meio empresarial como no familiar. Busca-se a sobrevivência de empresas familiares de maneira mais aguerrida ao longo prazo, em que os resultados financeiros em curto prazo, de certa forma, são consequências das ações da empresa pensando em longo prazo (Flores \& Grisci, 2012).

A ligação genética e dinâmica familiar são fatores intrínsecos de empresas familiares, que influenciam a forma de realizarem estratégias, controles gerenciais e obterem resultados. Empresas familiares, com controle ou gestão familiar, possuem características particulares, que, por consequência, geram efeitos positivos ou também negativos ao negócio, o que varia conforme o enraizamento da cultura do fundador e as estratégias de crescimento (Freire, Soares, Nakayama, \& Spanhol, 2010). 
A propriedade familiar pode gerar impactos positivos e negativos às empresas. Segundo Chen, Hsu, e Chen (2014), em empresas familiares, há menos assimetria de informação, conflitos de interesses e objetivos, em comparação com as empresas não familiares, ao considerar que os indivíduos da família concentram esforços para a concretização do objetivo da empresa, que é de sua propriedade. De acordo com Wang (2006), as empresas familiares possuem incentivos para fornecerem informações de qualidade aos usuários das demonstrações financeiras, visto que estes podem oferecer capital ao menor custo. Dessa forma, a qualidade da informação contábil de empresas familiares auxilia a diminuição da assimetria da informação com os usuários externos, o que pode acarretar a melhora da captação de recursos.

Entretanto, de acordo com Peng e Jiang (2010), a propriedade familiar pode gerar benefícios e custos às empresas. O impacto positivo e/ou negativo que a propriedade familiar gera nas organizações depende das instituições legais e regulamentares que regem a proteção dos investidores. A propriedade familiar, em empresas localizadas em países com instituições legais com poder e que regem normas a fim de aumentar a proteção de investidores, pode beneficiar a assimetria da informação. No entanto, em países com instituições reguladoras com menos poder em reger normas de proteção aos investidores, o controle da empresa dar-se-á por meio de gestores da família, podendo ocorrer a expropriação dos acionistas minoritários, o que agrava a assimetria da informação.

\section{Tempestividade da informação contábil}

A informação contábil contida nos relatórios financeiros é importante para a tomada de decisão dos usuários. A tempestividade dos relatórios contábeis é considerada uma das mais fundamentais características de informações da contabilidade financeira para a profissão contábil, para os usuários da informação e para as agências reguladoras (Soltani, 2002). Para Kazemi e Kola (2015), a tempestividade e a confiabilidade são os componentes mais importantes para determinar a qualidade das informações contábeis das empresas, uma vez que os usuários podem utilizar-se dela de modo útil.

As informações contábeis são tempestivas quando se registram as variações patrimoniais no momento em que o fato gerador ocorre, concedendo tempo suficiente para que os usuários dessas informações maximizem a sua utilidade. Por outro lado, se o registro não for tempestivo, as demonstrações contábeis mostrar-se-ão incompletas, fato que prejudicará as análises, prognósticos e diagnósticos, ou seja, deve-se evitar que os registros patrimoniais estejam desatualizados ou incompletos nas demonstrações financeiras (ludícibus, 2005).

A tempestividade, de acordo com o Conselho Federal de Contabilidade, na Resolução № 785 (1995), “refere-se ao fato de a informação contábil dever chegar ao conhecimento do usuário em tempo hábil, a fim de que este possa utilizá-la para seus fins" (p. 3). Além disso, é necessário que a periodicidade das informações que são preparadas e divulgadas de modo sistemático seja mantida.

De acordo com o CPC oo (2015), a tempestividade é uma das características qualitativas de melhoria da informação contábil, que significa a informação estar disponivel a tomadores de decisão em tempo hábil para influenciar suas decisões. Informações antigas possuem menos utilidade; todavia, se a informação for necessária para projeções futuras, terá a tempestividade prolongada.

De acordo com Tazik e Mohamed (2014), os usuários da informação financeira precisam que as informações sejam relevantes, confiáveis e tempestivas para sobreviverem em um ambiente competitivo. Nesse sentido, Bushman et al. (2004) ressaltam que os diretores externos exigem que as informações dos relatórios contábeis sejam tempestivas com o propósito de ajudá-los no acompanhamento das suas responsabilidades.

As informações oportunas são aquelas que incorporam renda econômica, ou seja, podem afetar a tomada de decisão de agentes econômicos, que, por sua vez, pode alterar o valor das ações (Bushman et al., 2004). Informações tempestivas são aquelas disponíveis em tempo hábil para a tomada de decisão de interessados. As propriedades timeliness da informação possuem similaridades de impactar o preço das ações, pela influência na tomada de decisões de agentes econômicos, visto o fornecimento de informações oportunas e tempestivas.

\section{Relação entre empresas familiares e tempestividade da informação contábil}

A qualidade da informação contábil e sua relação com a propriedade/ gestão familiar foi investigada em âmbitos internacional e nacional. No que se refere a pesquisas internacionais, Cascino et al. (2010) verificaram que a alta concentração de propriedade e a propriedade familiar produzem efeito positivo na qualidade da informação contábil em relação à qualidade dos accruals, persistência, previsibilidade, suavização de resultados, relevância da informação e conservadorismo, enquanto os resultados para a tempestividade não foram significantes. Os autores investigaram também se a propriedade familiar em empresas italianas afetava a qualidade de relatórios financeiros. Os resultados mostraram que 
as empresas familiares apresentaram qualidade da informação contábil superior em relação a empresas não familiares, fornecendo evidências sobre a influência positiva da propriedade familiar na qualidade de relatórios financeiros.

Lim, How, e Verhoeven (2014), usando dados em painel, encontraram uma relação não linear entre a propriedade concentrada das empresas e o atraso nos relatórios, analisando 1.276 empresas da Malásia de 1996 a 2009. Os resultados mostraram que empresas familiares apresentaram informações menos oportunas. Tal resultado pode ser decorrente da baixa necessidade de financiamento pelo mercado de ações de empresas com propriedade concentrada.

Fan e Wong (2002) analisaram as relações entre estrutura de propriedade e informatividade dos lucros de 977 empresas em sete economias no Leste Asiático. Os resultados mostraram que os proprietários controladores podem relatar informações financeiras por interesses próprios, e a propriedade concentrada mostrou-se associada com baixa informatividade nos lucros.

A literatura internacional utiliza o termo timeliness das informações contábeis como informação oportuna e tempestiva. Autores como Basu (1997) e Francis, Lafond, Olsson, e Schipper (2004) verificaram a oportunidade da informação contábil, enquanto Bushman et al. (2004), Lopes (2009), Almeida (2010) e Silva (2013) analisaram a tempestividade. Embora existam modelos econométricos distintos, pode-se dizer que, teoricamente, esses termos são equivalentes, relacionados à velocidade com que as informações contábeis estão disponíveis aos tomadores de decisão.

Em relação à tempestividade, Lopes (2009) verificou se a qualidade da informação em empresas brasileiras que adotavam padrões de governança era superior à de empresas que não operavam nesse mesmo regime. Os resultados demonstraram que as empresas com elevados padrões de governança apresentaram maior tempestividade, conservadorismo e relevância.

Almeida (2010) investigou o efeito do ambiente competitivo na qualidade da informação contábil divulgada pelas firmas brasileiras. Para verificar a qualidade da informação contábil, utilizou modelos para detectar o gerenciamento de resultados, o conservadorismo contábil, a tempestividade e a relevância da informação. Entre os resultados, em relação ao efeito do ambiente competitivo na tempestividade da informação, observou-se relação positiva, pela percepção dos gestores em potencializar informações para diminuição do grau de competição.

Silva (2013) investigou o impacto da adoção das IFRS na qualidade das demonstrações contábeis e no custo de capital de empresas brasileiras. Entre os modelos utilizados para verificar a qualidade da informação contábil, encontrava-se o da tempestividade. Os resultados demonstraram que a adoção das IFRS pelas empresas analisadas resultou em aumento da tempestividade da informação contábil.

Entre esses estudos supracitados, não se observou a relação entre empresas familiares e a tempestividade da informação contábil, o que torna propício este estudo. No entanto, essa falta de resultados empíricos dificulta o estabelecimento de hipóteses de pesquisa, visto que o resultado pode ser uma relação tanto positiva entre tempestividade e controle/gestão familiar quanto negativa.

De acordo com Flores e Grisci (2012), em empresas familiares, as ações e atitudes são traçadas pensando-se nos benefícios em longo prazo, sendo os resultados de curto prazo consequências das ações de longo prazo. Dessa forma, acredita-se que, para ter benefícios no longo prazo, as empresas familiares terão de ter transparência em suas evidenciações, reportando informações de maior qualidade, inclusive informações mais tempestivas, que possam reduzir seu custo de capital.

Além disso, nesse tipo de empresa, pode haver o que Shleifer e Vishny (1997) chamam de efeito alinhamento, em que grandes acionistas (família) possuem maiores incentivos para monitorar os gestores, fazendo com que as informações a serem divulgadas sejam mais tempestivas. Por outro lado, pode haver um efeito entrincheiramento (Demsetz, 1983), na medida em que o acionista principal (família) procura expropriar os acionistas minoritários, surgindo incentivos para menor transparência nas informações contábeis, com possível redução de sua tempestividade.

Assim, dados a falta de resultados empíricos consistentes e o framework teórico não conclusivo quanto à influência positiva ou negativa do controle/gestão familiar sobre a tempestividade das informações contábeis, optou-se por se estabelecer uma hipótese geral, mas sem indicação de sinal da relação esperada, conforme segue:

H1: Há uma relação estatisticamente significativa entre o controle/gestão familiar e a tempestividade da informação contábil.

\section{PROCEDIMENTOS METODOLÓGICOS}

Para analisar a tempestividade da informação contábil em empresas familiares brasileiras, realizou-se uma pesquisa descritiva, documental quanto aos procedimentos técnicos e com abordagem quantitativa.

\section{População e amostra}

A população da pesquisa compreendeu todas as empresas listadas na Bolsa de Valores, Mercadorias e Futuros de São Paulo 
(BM\&FBOVESPA). A amostra foi composta por 124 empresas, as quais dispunham de todas as informações necessárias para a realização da pesquisa. Das 124 empresas da amostra, 41 apresentavam gestão familiar e 8, controle familiar, as quais, em conjunto, representaram as empresas familiares da amostra. Os dados foram coletados anualmente, no período compreendido entre os anos de 2010 a 2013. No Quadro 1, apresenta-se a amostra do estudo, segmentada nos setores de atuação.

\section{Quadro 1. Amostra da pesquisa}

\begin{tabular}{|c|c|}
\hline Bens industriais & Construção e transporte \\
\hline $\begin{array}{l}\text { Csu Cardsyst; Dtcom Direct; Embraer; Inds Romi; Inepar; lochp- } \\
\text { Maxion; Kepler Weber; Lupatech; Marcopolo; Metalfrio; Plascar Part; } \\
\text { Randon Part; Valid; Weg. }\end{array}$ & $\begin{array}{l}\text { Arteris; BR Brokers; Brookfield; CCR AS; Cr2; Cyrela Realt; Eternit; } \\
\text { Even; Eztec; Gafisa; Helbor; JHSF Part; João Fortes; Log-In; Lopes } \\
\text { Brasil; MRV; PDG Realt; Portobello; Prumo; Rodobensimob; Rossi } \\
\text { Resid; Tecnisa; Tegma; Trisul; Triunfo Part; Viver; Wilson Sons. }\end{array}$ \\
\hline Consumo cíclico & Consumo não cíclico \\
\hline $\begin{array}{l}\text { B2W Digital; BHG; Cia. Hering; Estácio Part; Grendene; Guararapes; } \\
\text { IGB S/A; Le Lis Blanc; Localiza; Lojas Americanas; Lojas Marisa; Lojas } \\
\text { Renner; Springs. }\end{array}$ & $\begin{array}{l}\text { Ambev S/A; BRF AS; Cremer; Dasa; Dimed; Hypermarcas; JBS; } \\
\text { M.Diasbranco; Marfrig; Minerva; Natura; Odontoprev; Profarma; } \\
\text { RaiaDrogasil; Renar; São Martinho; SLC Agrícola; Souza Cruz; Tempo } \\
\text { Part; V-Agro. }\end{array}$ \\
\hline Financeiro e outros & Materiais básicos \\
\hline $\begin{array}{l}\text { Amazônia; Banestes; BmfBovespa; BR Malls Par; Bradesco; } \\
\text { Bradespar; Brasil; Cyre Com-Ccp; Generalshopp; Iguatemi; } \\
\text { ItaúUnibanco; Multiplan Porto Seguro; São Carlos; Ultrapar. }\end{array}$ & $\begin{array}{l}\text { Duratex; Fer Heringer; Gerdau; Gerdau Met; Magnesita AS; MMX } \\
\text { Miner; Paranapanema; Providência; Sid Nacional; Usiminas; Vale. }\end{array}$ \\
\hline Petróleo, gás e biocombustíveis & Tecnologia da informação \\
\hline OGX Petróleo; Petrobras. & Bematech; Ideiasnet; Positivo Inf; Totvs. \\
\hline Telecomunicações & Utilidade pública \\
\hline Embratel Part; Inepar Tel; Oi; Telef Brasil; Tim Part S/A. & $\begin{array}{l}\text { AES Tietê; Cemig; Cesp; Copasa; Copel; CPFL Energia; Eletrobrás; } \\
\text { Energias BR; Eneva; Equatorial; Light S/A; Sabesp; Tractebel. }\end{array}$ \\
\hline
\end{tabular}

\section{Coleta e análise dos dados}

Para a coleta de dados, utilizaram-se a base de dados Economática ${ }^{\circledR}$ e o Formulário de Referência das empresas, disponibilizado no website da BM\&FBOVESPA. As informações econômico-financeiras foram coletadas na base de dados Economática ${ }^{\circledR}$, enquanto os dados necessários para 0 enquadramento das empresas em familiar ou não familiar foram verificados nos seus Formulários de Referência.

Para o enquadramento das empresas como familiares ou não familiares, utilizaram-se os conceitos de Porta, Lopezde-Dilanes, e Shleifer (1999), visto que uma das principais preocupações em estudos com empresas familiares é a sua identificação. Dessa forma, de acordo com esses autores, para a identificação das empresas familiares, verifica-se a posse acionária de membros familiares, se estes possuem mais que
$10 \%$ das ações da firma, bem como se estavam presentes no conselho de administração, para o enquadramento da empresa com propriedade familiar.

No atual estudo, verificaram-se empresas com controle e gestão familiar, sendo as empresas que apresentavam ou controle ou gestão familiar, consideradas como familiares. Para o enquadramento das empresas com controle familiar, foi analisado se a percentagem de participação dos membros familiares na empresa era superior a $10 \%$ das ações. Para o enquadramento das empresas com gestão familiar, verificou-se se dois ou mais membros da família faziam parte do conselho de administração.

Para capturar a tempestividade da informação contábil, foram utilizadas equações baseadas no modelo de tempestividade da informação contábil adotado por Bushman et al. (2004) e Lopes (2009). Demonstram-se, no Quadro 2, as variáveis utilizadas no estudo. 


\section{Quadro 2. Variáveis do estudo}

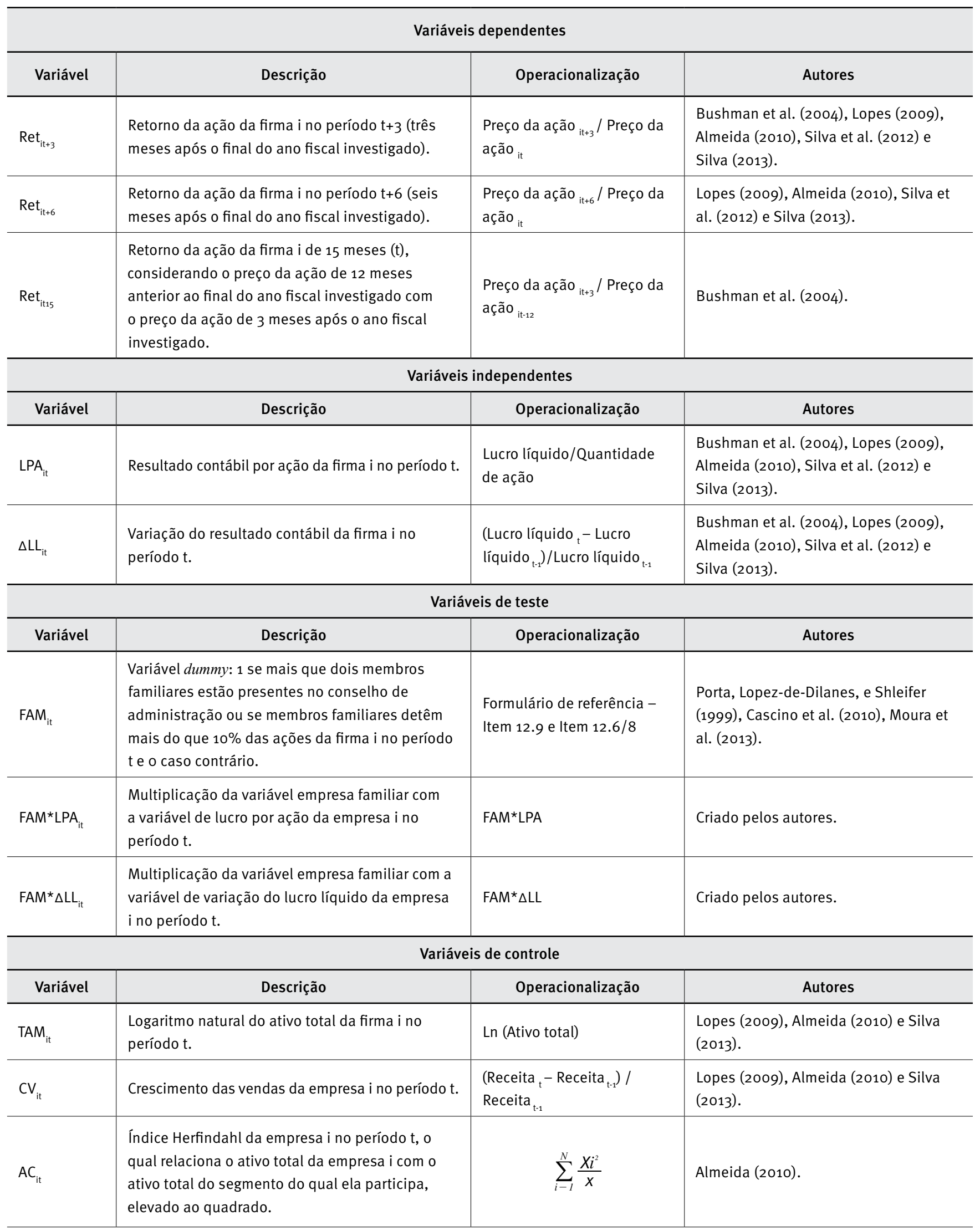


De acordo com Bushman et al. (2004), Lopes (2009) e Almeida (2010), para tentar captar por meio de modelos estatísticos a característica de tempestividade da informação, mede-se o impacto de informações contábeis como lucro por ação e a variação do lucro sobre o retorno da ação. Caso a informação contábil (lucro) tenha influenciado significativamente o retorno, pode-se inferir que ela foi tempestiva o suficiente para impactar a decisão do investidor, o que reflete no retorno das ações.

Dessa forma, foram rodadas equações a fim de avaliar o $\mathrm{R}^{2}$ de cada modelo, em que esse $R^{2}$ representa o poder explicativo, ou seja, o quanto as informações contábeis são tempestivas para impactar as decisões dos investidores. Para responder à questão de pesquisa, foram comparados os $\mathrm{R}^{2}$ entre empresas familiares e não familiares.

Lopes (2009) considera que o lucro pode influenciar o preço durante um longo período. Desse modo, a especificação do modelo que analisa a tempestividade da informação contábil, conforme o Quadro 2, procura observar se o lucro corrente influencia o retorno corrente, ou seja, se o lucro e a variação do lucro podem explicar o retorno contemporâneo das ações.

De acordo com as variáveis apresentadas no Quadro 2, foram elaboradas três equações para a análise dos dados. Essas equações diferenciaram-se pelas variáveis dependentes de retorno da ação. $O$ modelo utilizado por Bushman et al. (2004) considera o retorno de 15 meses, determinando como data final três meses após o encerramento do exercício. Assim, para informações do ano de 2010, foi considerado o retorno do período entre os dias 31/12/2009 e 31/3/2011. Como análises adicionais, foram considerados também períodos de retorno mais curtos, como de três meses $\left(\operatorname{Ret}_{\mathrm{it}+3}\right)$, e de seis meses $\left(\operatorname{Ret}_{\mathrm{it}+6}\right)$. Considerando que as demonstrações contábeis são publicadas, geralmente, em média, três meses após o encerramento do exercício, o retorno de três meses procura capturar reações imediatas dos investidores em relação às informações contábeis divulgadas. Já o modelo de seis meses tem um horizonte um pouco maior, mas ainda de curto prazo, tentando capturar o efeito das informações contábeis nos três meses seguintes a sua publicação.

As três equações apresentaram como variáveis independentes o lucro por ação (LPA) e a variação do lucro $(\Delta \mathrm{LL})$, que são constantes no modelo original. Além disso, foram acrescentadas variáveis de controle, tais como tamanho da empresa (TAM), crescimento das vendas (CV) e ambiente competitivo (AC). 0 crescimento nas vendas e o tamanho elevado alteram a qualidade da informação contábil. O tamanho da empresa pode auxiliar o aumento da qualidade da informação (Almeida, 2010; Silva, 2013), por geralmente estarem sujeitas a maior monitoramento, tanto interno quanto externo, enquanto empresas com crescimento nas vendas podem ter menor qualidade da informação contábil, por utilizar a conta vendas para mascarar os resultados (Lopes, 2009). Em ambientes competitivos, a informação contábil pode ser afetada, visto que gestores potencializam informações contábeis para diminuir o grau de competitividade entre as empresas (Almeida, 2010).

Para comparar a tempestividade entre empresas familiares e não familiares, as três equações foram aplicadas em amostras separadas (de empresas não familiares e familiares), como também em uma amostra global com todas as empresas em conjunto, sendo, para a identificação das empresas familiares nesse modelo, adicionadas variáveis dummy de empresa familiar (FAM), variável de multiplicação entre FAM e lucro por ação (FAM*LPA) e variável de multiplicação entre FAM e variação do lucro líquido $\left(F A M^{*} \Delta \mathrm{LL}\right)$, a fim de capturar a tempestividade nas empresas familiares.

Conforme já comentado, as três equações apresentaram como variável dependente o retorno da ação de três, seis e 15 meses, respectivamente. Os modelos econométricos estão demonstrados na sequência.

(1) $\operatorname{Ret}_{\mathrm{it}+3}=\mathrm{b}_{\mathrm{o}}+\mathrm{b}_{1} \mathrm{LPA}_{\mathrm{it}}+\mathrm{b}_{2} \Delta \mathrm{LL}_{\mathrm{it}}+\mathrm{b}_{3} \mathrm{TAM}_{\mathrm{it}+} \mathrm{b}_{4} \mathrm{CV}_{\mathrm{it}+} \mathrm{b}_{5} \mathrm{AC}_{\mathrm{it}+} \mathrm{e}_{\mathrm{it}}$ (1a)

Ret $_{i t+3}=b_{0}+b_{1} L A_{i t}+b_{2} \Delta L L_{i t}+b_{3} F A M_{i t}+b_{4} F A M * L A_{i t}+b_{5}$ $F A M^{*} \Delta \mathrm{LL}_{\mathrm{it}}+\mathrm{b}_{6} \mathrm{TAM}_{\mathrm{it}+} \mathrm{b}_{7} \mathrm{CV}_{\mathrm{it}+} \mathrm{b}_{8} A \mathrm{C}_{\mathrm{it}+} \mathrm{e}_{\mathrm{it}}$

(2)

$\operatorname{Ret}_{i t+6}=b_{0}+b_{1} L P A_{i t}+b_{2} \Delta L_{i t}+b_{3} T_{A M} b_{t+} b_{4} C V_{i t}+b_{5} A C_{i t} e_{i t}$

(2a)

$\operatorname{Ret}_{\mathrm{it}+6}=\mathrm{b}_{\mathrm{o}}+\mathrm{b}_{1} \mathrm{LPA}_{\mathrm{it}}+\mathrm{b}_{2} \Delta \mathrm{LL}_{\mathrm{it}}+\mathrm{b}_{3} \mathrm{FAM}_{\mathrm{it}}+\mathrm{b}_{4} \mathrm{FAM}^{\star} \mathrm{LPA}_{\mathrm{it}}+\mathrm{b}_{5}$ $F A M^{*} \Delta \mathrm{LL}_{\mathrm{it}}+\mathrm{b}_{6} \mathrm{TAM}_{\mathrm{it}+} \mathrm{b}_{7} \mathrm{CV}_{\mathrm{it}+} \mathrm{b}_{8} \mathrm{AC}_{\mathrm{it}+} \mathrm{e}_{\mathrm{it}}$

(3)

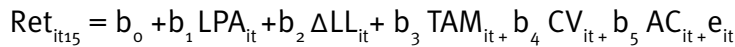

(3a)

$\operatorname{Ret}_{\mathrm{it} 15}=\mathrm{b}_{0}+\mathrm{b}_{1} \mathrm{LPA}_{\mathrm{it}}+\mathrm{b}_{2} \Delta \mathrm{LL}_{\mathrm{it}}+\mathrm{b}_{3} \mathrm{FAM}_{\mathrm{it}}+\mathrm{b}_{4} F A \mathrm{FA}^{\star} \mathrm{LPA}_{\mathrm{it}}+\mathrm{b}_{5}$ $\mathrm{FAM}^{*} \Delta \mathrm{LL}_{\mathrm{it}}+\mathrm{b}_{6} \mathrm{TAM}_{\mathrm{it}+} \mathrm{b}_{7} \mathrm{CV}_{\mathrm{it}+} \mathrm{b}_{8} \mathrm{AC}_{\mathrm{it}+} \mathrm{e}_{\mathrm{it}}$

As equações 1,2 e 3 foram rodadas e analisadas separando-se as amostras em empresas familiares e não familiares, a fim de identificar o $\mathrm{R}^{2}$ de cada modelo, o qual representa a tempestividade da informação contábil. Já as equações 1a, 2 a e za foram rodadas e analisadas com a amostra global (tanto familiar quanto não familiar), acrescentando as variáveis dummies de empresas familiares, com o objetivo de identificar se estas acrescentam informações importantes para aumentar o poder de explicação do modelo, ou seja, da tempestividade da informação contábil.

Com base nas equações de 1 a 3, a análise dos dados foi realizada pela utilização de técnicas estatísticas, como estatística descritiva, por meio do software SPSS ${ }^{\circledR}$, além de regressão de dados em painel, com a utilização do software STATA ${ }^{\circledR}$. 


\section{APRESENTAÇÃO E ANÁLISE DOS RESULTADOS}

\section{Estatística descritiva}

Apresentam-se, nesta seção, a descrição e a análise dos resultados. A Tabela 1 apresenta a estatística descritiva das variáveis: retorno das ações de três, seis meses depois de

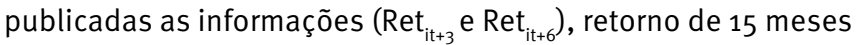
$\left(\operatorname{Ret}_{\text {it15 }}\right)$, lucro por ação (LPA), variação do lucro $(\Delta \mathrm{LL})$, tamanho da empresa (TAM), crescimento das vendas (CV) e ambiente competitivo (AC). As demais variáveis não foram analisadas por meio de estatística descritiva, pois corresponderam a variáveis dummies que variam de o a 1, somente.

\section{Tabela 1. Estatística descritiva}

\begin{tabular}{c|c|c|c|c}
\hline Variáveis & Mínimo & Máximo & Média & $\begin{array}{c}\text { Desvio } \\
\text { padrão }\end{array}$ \\
\hline Ret $_{\mathrm{it}+3}$ & 0,497 & 1,709 & 1,019 & 0,166 \\
\hline Ret $_{\mathrm{it}+6}$ & 0,180 & 1,943 & 0,969 & 0,233 \\
\hline $\mathrm{Ret}_{\mathrm{it} 15}$ & $-0,943$ & 2,253 & 0,088 & 0,449 \\
\hline $\mathrm{LPA}_{\mathrm{it}}$ & $-5,388$ & 14,139 & 1,146 & 1,941 \\
\hline$\Delta \mathrm{LL}_{\mathrm{it}}$ & $-261,800$ & 40,159 & $-0,376$ & 12,157 \\
\hline $\mathrm{TAM}_{\mathrm{it}}$ & 9,662 & 20,989 & 15,471 & 1,705 \\
\hline $\mathrm{CV}_{\mathrm{it}}$ & $-1,000$ & 3,392 & 0,167 & 0,331 \\
\hline $\mathrm{AC}_{\mathrm{it}}$ & 0,000 & 0,986 & 0,024 & 0,095
\end{tabular}

De acordo com a Tabela 1, pode-se verificar que o mínimo do retorno das ações três $\left(\operatorname{Ret}_{i t+3}\right)$ e seis $\left(\operatorname{Ret}_{i t+6}\right)$ meses após a publicação das informações do trimestre anterior correspondeu a 0,497 e 0,180, respectivamente, o máximo a 1,709 ( Ret $\left._{\mathrm{it}+3}\right)$ e 1,943 $\left(\operatorname{Ret}_{\mathrm{it}+6}\right)$. Os desvios padrões de 0,166 e 0,233 demonstraram pouca variância do retorno das ações em relação às médias de $1,019\left(\operatorname{Ret}_{i t+3}\right)$ e 0,969 $\left(\operatorname{Ret}_{i t+6}\right)$. Observa-se que o retorno da ação seis meses depois de publicadas as informações manteve-se semelhante ao retorno da ação de três meses.

Quanto ao retorno da ação de 15 meses $\left(\right.$ Ret $\left._{\text {it15 }}\right)$, observou-se média baixa de 0,088 em relação aos demais retornos analisados, além de demonstrar, pelo valor mínimo, que algumas empresas tiveram diminuição do preço de suas ações com o passar do tempo.

Em relação ao lucro por ação (LPA) e à variação do lucro $(\Delta \mathrm{LL})$, percebeu-se que algumas empresas apresentaram valores negativos, sendo o valor máximo observado de 14,139 (LPA) e 40,159 ( $\Delta \mathrm{LL})$. 0 desvio padrão elevado de ambas as variáveis demonstrou que muitas empresas apresentaram valores discrepantes em relação à média de 1,146 e -0,376, respectivamente, possuindo a média das empresas variação do lucro por ação negativa.
O logaritmo natural do ativo total (TAM) demonstrou desvio padrão baixo $(1,705)$, se comparado à média. 0 crescimento das vendas (CV) demonstrou índice médio em torno de $16 \%$, com desvio padrão elevado $(0,331)$, o que mostra elevada dispersão nos dados. A variável de ambiente competitivo (AC), que vai de o a 1, em que, quanto mais perto de o, maior é o ambiente competitivo do setor da empresa, por apresentar média 0,024, representa que a maioria das empresas opera em um ambiente altamente competitivo. Em relação ao valor máximo de 0,986, este corresponde às empresas do setor de petróleo, o qual é operado por poucas empresas.

\section{Análise dos modelos de tempestividade}

Após analisada a estatística descritiva das variáveis, foram aplicados os testes de Durbin-Watson, Shapiro-Wilk e Levene às variáveis de teste para verificar a aleatoriedade, normalidade e homoscedasticidade dos dados, respectivamente. Observou-se que inexiste autocorrelação de primeira ordem entre os resíduos, que a distribuição dos resíduos é normal e a variância dos erros, uniforme, atendendo aos pressupostos para análise multivariada em todos os modelos. Dessa forma, depois de verificados os pressupostos dos modelos de regressão de dados em painel, apresentam-se, na Tabela 2, os resultados oriundos das equações 1 e 1 .

Conforme informações constantes na Tabela 2, pode-se observar que a equação 1 , tanto para empresas familiares quanto não familiares, não se demonstrou significativa na amostra analisada, assim como a equação 1a. Assim, pode-se inferir que, na amostra e no período analisados, as informações de lucro por ação (LPA), variação do lucro líquido $(\Delta \mathrm{LL})$, tamanho da empresa (TAM), crescimento das vendas (CV), bem como as informações de empresas familiares (FAM; FAM*LPA; $\left.F A M^{\star} \Delta L L\right)$ e ambiente competitivo (AC), não se demonstraram significativas para impactar a decisão de investidores, o que poderia ser refletido no retorno da ação de três meses. Ou seja, as informações contábeis das empresas divulgadas no final do exercício não foram tempestivas o suficiente para impactar a decisão do investidor três meses após o término do exercício. Tal resultado pode ser decorrente de que as informações contábeis tenham sido divulgadas após o terceiro mês do exercício social seguinte, ou porque outros fatores tenham influenciado o retorno da ação nesse período, o que constitui uma limitação do modelo estatístico utilizado. Dessa forma, essa constatação pode sugerir que as informações contábeis teriam maior tempestividade sobre o retorno de seis meses depois de publicadas as informações, visto que, nesse período, todas as informações do exercício anterior já teriam sido divulgadas. 
Tabela 2. Análise de regressão de dados em painel - Equações 1 e 1a

\begin{tabular}{|c|c|c|c|c|c|c|}
\hline \multirow{2}{*}{ Variáveis } & \multicolumn{2}{|c|}{ POLS } & \multicolumn{2}{|c|}{ POLS } & \multicolumn{2}{|c|}{ POLS } \\
\hline & Coefic. & Sig. & Coefic. & Sig. & Coefic. & Sig. \\
\hline $\mathrm{LPA}_{\text {it }}$ & 0,012 & 0,034 & $-0,000$ & 0,863 & 0,011 & 0,040 \\
\hline$\Delta \mathrm{LL}_{\mathrm{it}}$ & 0,000 & 0,645 & $-0,008$ & 0,004 & 0,000 & 0,705 \\
\hline $\mathrm{FAM}^{*} \mathrm{LPA}_{\mathrm{it}}$ & $\cdots-\cdots$ & $\cdots-\cdots$ & -..-.- & $\cdots+\cdots$ & $-0,012$ & 0,102 \\
\hline $\mathrm{FAM}^{*} \Delta \mathrm{LL}_{\mathrm{it}}$ & -.-.- & -.-.- & -.-.- & -..-- & $-0,008$ & 0,004 \\
\hline $\mathrm{TAM}_{i t}$ & $-0,000$ & 0,882 & 0,003 & 0,638 & 0,000 & 0,873 \\
\hline $\mathrm{CV}_{\text {it }}$ & $-0,025$ & 0,465 & $-0,013$ & 0,652 & $-0,016$ & 0,458 \\
\hline$A C_{i t}$ & 0,004 & 0,959 & $-0,650$ & 0,117 & $-0,033$ & 0,702 \\
\hline Teste F & \multicolumn{2}{|c|}{0,3234} & \multicolumn{2}{|c|}{0,0669} & \multicolumn{2}{|c|}{0,0799} \\
\hline LM de Breusch-Pagan & \multicolumn{2}{|c|}{$\operatorname{Sig} X^{2} 0,1895$} & \multicolumn{2}{|c|}{$\operatorname{Sig} X^{2} 1,0000$} & \multicolumn{2}{|c|}{$\operatorname{Sig} X^{2} 1,0000$} \\
\hline Teste de Chow & \multicolumn{2}{|c|}{ Sig. F 0,5710 } & \multicolumn{2}{|c|}{ Sig. F o,9662 } & \multicolumn{2}{|c|}{ Sig. F 0,9933 } \\
\hline Teste de Hausman & \multicolumn{2}{|c|}{ Sig. $X^{2}$-..-- } & \multicolumn{2}{|c|}{ Sig. X² ----- } & \multicolumn{2}{|c|}{ Sig. X² ----- } \\
\hline $\mathrm{N}$ & \multicolumn{2}{|c|}{270} & \multicolumn{2}{|c|}{226} & \multicolumn{2}{|c|}{496} \\
\hline
\end{tabular}

Apresenta-se, a seguir, a Tabela 3 com a regressão de dados em painel das equações 2 e $2 a$.

Tabela 3. Análise de regressão de dados em painel - Equações 2 e $2 a$

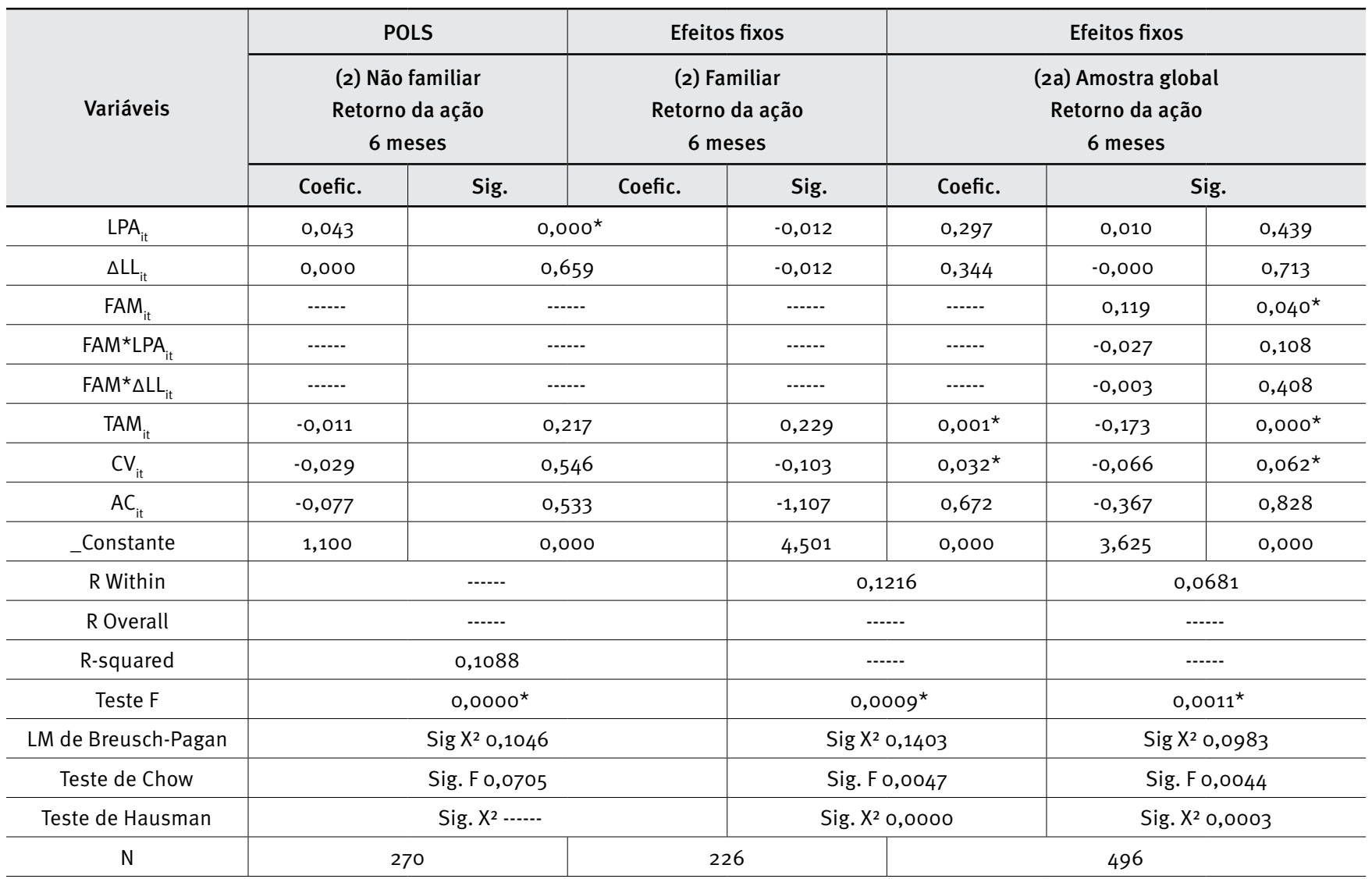


Em relação às equações 2 e $2 a$, apresentadas na Tabela 3 , estas se demonstraram significativas a $5 \%$, tanto para as empresas familiares ou não familiares quanto para a amostra global, em que o $\mathrm{R}^{2}$ se demonstrou mais elevado para a amostra de empresas familiares $(0,1216)$, o que sugere que, em empresas familiares, há maior tempestividade de informações contábeis. Além disso, observou-se que o tamanho (TAM) e crescimento das vendas (CV) também foram significativos para explicar o retorno das ações. No entanto, o TAM apresentou-se com final inverso ao esperado. É importante destacar que as informações contábeis somente foram significativas para as empresas não familiares em relação ao lucro por ação (LPA). Portanto, apesar do maior $\mathrm{R}^{2}$ no modelo de empresas familiares, não é possível afirmar que as informações contábeis dessas empresas são mais tempestivas.

Já para a equação de amostra global, constatou-se que também as variáveis tamanho da empresa (TAM) e crescimento das vendas (CV) foram novamente significativas para explicar o retorno das ações. Também a variável de empresa familiar (FAM) apresentou impacto positivo no retorno da ação de seis meses $\left(\operatorname{Ret}_{\mathrm{it}+6}\right)$, o que sugere que, em empresas familiares, há maior retorno da ação.

Apresentam-se, na Tabela 4, os resultados das equações 3 e 3 a aplicados tanto na amostra de empresas familiares ou não familiares quanto na amostra global.

Tabela 4. Análise de regressão de dados em painel - Equações 3 e $3 a$

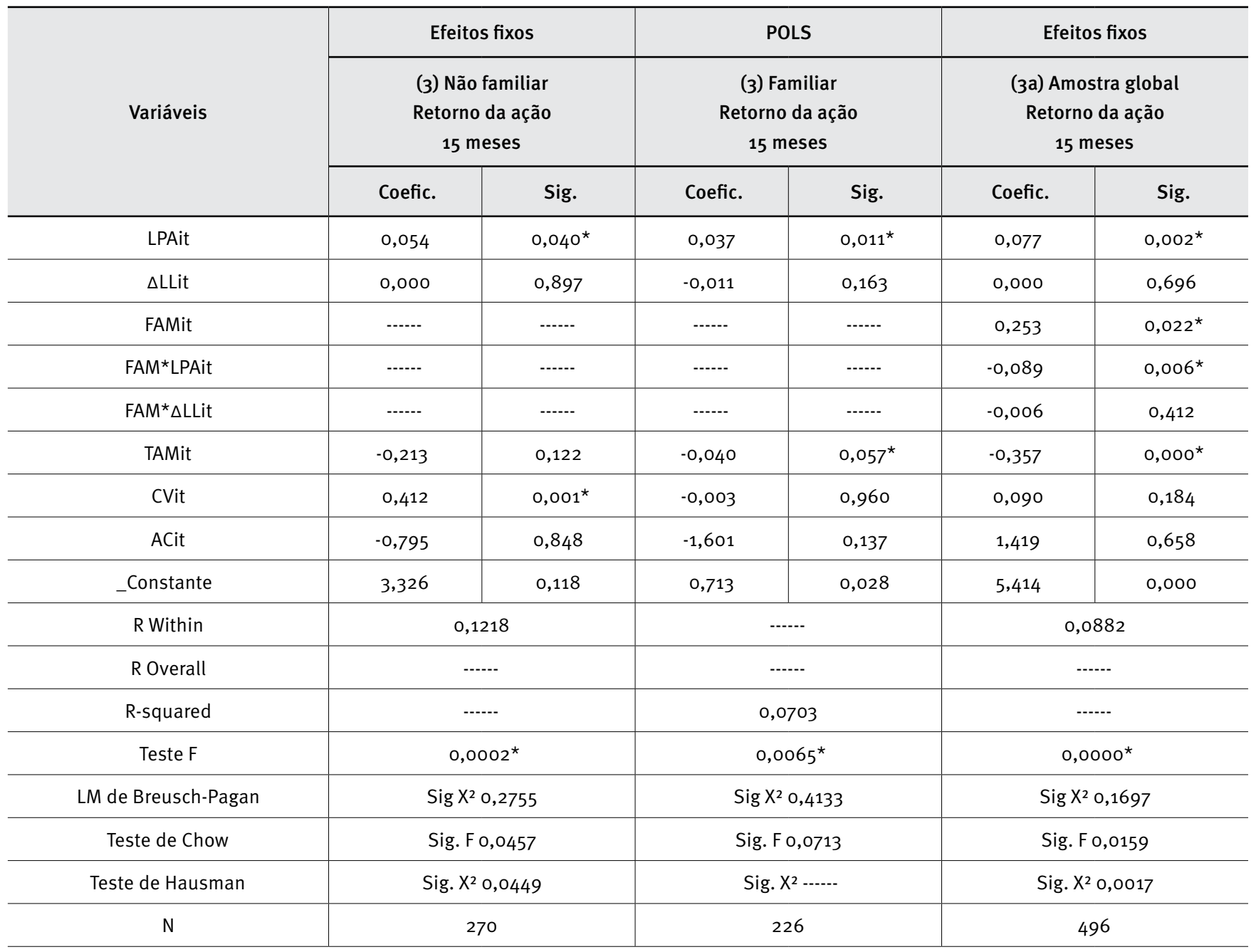

Em relação à Tabela 4, pode-se observar que as equações 3 e 3a aplicadas às amostras de empresas familiares, não familiares e global demonstraram-se significativas a $5 \%$, apresentando-se o poder de explicação do modelo maior para a amostra de empresas não familiares $(0,1218)$. Tal resultado é divergente em relação aos modelos anteriores, entretanto esse resultado pode ser ocasionado pela análise das informações tempestivas para os investidores considerando o retorno das ações de 15 meses, portanto com um horizonte temporal mais de longo prazo, diferente dos modelos anteriores (seis e três meses). 
Em relação às informações contábeis que se demonstraram significativas, observou-se o lucro por ação (LPA) e crescimento das vendas (CV) para as empresas não familiares e lucro por ação (LPA) e tamanho da empresa (TAM) para as empresas familiares e para a amostra global.

Em relação à equação com amostra global, observou-se que a variável de empresa familiar (FAM) impactou positivamente o retorno da ação de 15 meses ( Reti $_{\text {t15 }}$ ), o que se pode inferir que, em empresas familiares, houve um maior retorno das ações. Entretanto, não se pode afirmar que esse resultado seja oriundo somente da divulgação de informações contábeis, podendo ser ocasionado também por informações não contábeis. Ainda, a variável FAM*LPA, que representa o lucro por ação somente de empresas familiares, demonstrou influência significativa sobre o retorno das ações de 15 meses ( Reti $_{\text {t15 }}$ ).

Considerando as três equações da Tabela 4, pode-se afirmar, de maneira geral, que as informações contábeis (LPA) de empresas familiares foram menos tempestivas do que nas empresas não familiares, o que fica comprovado pelo maior $\mathrm{R}^{2}$ da equação de empresas não familiares $(12,18 \%)$ em relação às empresas familiares (7,03\%). Além disso, no modelo global, a variável FAM*LPA apresentou-se negativa e significativa, indicando que, em empresas familiares, a influência do LPA sobre o retorno é menor, indicando menor tempestividade dessa informação nas empresas familiares.

\section{Discussão dos resultados}

Apresenta-se, nesta seção, uma discussão dos resultados encontrados quanto à tempestividade da informação contábil em empresas familiares. Infere-se que os resultados verificados devem ser interpretados com cuidado, visto que os modelos apresentaram resultados distintos conforme a variável dependente utilizada. Nos modelos com retornos de curtíssimo (três meses) e curto prazo (seis meses), apesar de os modelos sugerirem maior associação das variáveis preditoras com a variável dependente nas empresas familiares, as variáveis contábeis (LPA e $\Delta \mathrm{LL}$ ) não foram significativas, não sendo possível afirmar que as informações contábeis de tais empresas foram mais tempestivas.

Entretanto, quando considerado um horizonte temporal mais longo para o retorno das ações (15 meses), verificou-se que as informações contábeis (pelo menos o LPA) demonstraram-se mais tempestivas para as empresas não familiares. Dessa forma, pode-se inferir que, nesse caso, os controladores/ gestores das empresas familiares podem estar evidenciando informações não tempestivas, o que Demsetz (1983) chama de efeito entrincheiramento, na medida em que o acionista principal (família) procura expropriar os acionistas minoritários, surgindo incentivos para menor transparência nas informações contábeis com possível redução de sua tempestividade.

Além disso, empresas com controle e gestão familiar demonstram menos conflitos de interesses entre principais e agentes, visto que os gestores familiares concentram esforços para a concretização do objetivo da empresa, que retorna em benefícios para a família (Chen, Hsu, \& Chen, 2014). Assim, o fato de as informações contábeis de empresas familiares mostrarem-se menos tempestivas (ao menos no modelo de 15 meses) reforça a visão de possível conflito entre os acionistas majoritários (família) e demais acionistas minoritários, com aumento da assimetria de informações entre esses dois grupos de usuários.

Com base no exposto, rejeita-se a hipótese da pesquisa $\left(\mathrm{H}_{1}\right)$, que previa uma relação estatisticamente significativa entre o controle/gestão familiar e a tempestividade da informação contábil.

Esse resultado coaduna o encontrado por Lim et al. (2014), em empresas da Malásia entre 1996 e 2009, e Fan e Wong (2002), em sete economias no Leste Asiático, os quais constataram menor tempestividade e informatividade dos lucros, respectivamente, em empresas de controle/gestão familiar. É importante considerar a diferença de contextos entre esses dois estudos e este atual, em termos de tamanho do mercado de capitais, desenvolvimento econômico, estruturas de governança e outros fatores não considerados neste estudo. É possível que fatores exógenos possam influenciar o retorno das ações, o que pode criar um viés na análise. A falta de coerência entre os resultados das equações 1 e 2 (modelos de curto prazo) e da equação 3 (longo prazo) reforça essa percepção.

No entanto, essa é uma limitação inerente a todos os modelos econométricos, e o modelo estatístico utilizado neste estudo tem sido amplamente aplicado em estudos nacionais e internacionais para capturar o efeito da tempestividade da informação contábil.

Os achados corroboram também os encontrados por Almeida (2010) e Silva et al. (2012), em relação à influência do lucro no retorno das ações; por Lopes (2009), quanto ao crescimento das vendas; e por Almeida (2010), em relação ao tamanho da empresa.

\section{CONSIDERAÇÕES FINAIS}

O estudo teve como objetivo analisar a tempestividade da informação contábil em empresas familiares brasileiras. Para tanto, foi realizada uma pesquisa descritiva, documental e 
com abordagem quantitativa. A amostra foi composta por 124 empresas, com dados coletados anualmente, no período entre os anos de 2010 a 2013.

As variáveis dependentes da regressão de dados em painel que compõem o estudo foram o retorno da ação da firma, três e seis meses depois de divulgadas as informações contábeis, além do retorno de 15 meses. Já as variáveis independentes foram compostas pelo lucro por ação, variação do resultado contábil, variáveis independentes de empresa familiar, acrescidas de variáveis de controle relativas ao tamanho da empresa, ao crescimento das vendas e ao ambiente competitivo. Essas variáveis foram distribuídas em três equações de regressão de dados em painel para empresas familiares e não familiares e subequações, considerando as empresas familiares e não familiares em conjunto.

Por meio da análise de tais equações, verificou-se que as variáveis lucro por ação, tamanho da empresa e crescimento das vendas foram significativas para explicar o retorno das ações. Em relação às variáveis de interesse do estudo, de maneira geral, conclui-se que empresas familiares apresentaram menor tempestividade da informação contábil (quando analisado o modelo de longo prazo - equações 3 e 3a). Infere-se, assim, que controladores/gestores de empresas familiares podem retardar a divulgação de demonstrações financeiras aos agentes econômicos, ocasionando assimetria da informação e possível tentativa de expropriação de acionistas minoritários.

Todavia, tal efeito não foi observado quando considerados modelos de retorno de curto prazo (três e seis meses), o que limita, de certa forma, as conclusões do estudo sobre a tempestividade das informações contábeis de empresas familiares. Além disso, observou-se que não somente informações contábeis foram significativas para explicar o retorno das ações, o que sugere que outras variáveis ainda poderiam ser acrescidas ao modelo para elevar o $\mathrm{R}^{2}$ (proxy de tempestividade) encontrado. Dessa forma, sugere-se, em estudos futuros, a inclusão de outras variáveis no modelo de tempestividade, a fim de contribuir com a análise desse fenômeno em empresas familiares.

A pesquisa apresenta limitações, principalmente no que se refere à amostra ser pouco representativa, uma vez que nem todas as empresas dispunham das informações necessárias para a realização da pesquisa. Todavia, devido à quantidade de observações analisadas, tal limitação não compromete a contribuição dos resultados. Outra limitação refere-se à análise de uma característica qualitativa da informação contábil por meio de testes econométricos, necessários para estudos quantitativos, mas que podem resultar em variáveis omitidas e outros vieses de análise. Entretanto, tal estudo pode contribuir para as pesquisas na linha positiva da contabilidade, em que se analisam, por meio de teste econométricos, fenômenos contábeis. Espera-se que os achados deste estudo possam ser ampliados e complementados em estudos futuros, com a utilização de outras variáveis ou de empresas de um mesmo segmento, podendo abranger um período maior de análise.

\section{REFERÊNCIAS}

Almeida, J. E. F. (2010). Qualidade da informação contábil em ambientes competitivos (Tese de doutorado em Ciências Contábeis, Programa de Pós-Graduação em Ciências Contábeis, Departamento de Contabilidade e Atuária, Faculdade de Economia, Administração e Contabilidade, Universidade de São Paulo).

Alves, S. (2012). Ownership structure and earnings management: Evidence from Portugal. Australasian Accounting Business and Finance Journal, 6(1), 57-74.

Anderson, R. C., \& Reeb, D. M. (2003). Founding-family ownership and firm performance: Evidence from the S\&P 500. The Journal of Finance, 58(3), 1301-1328.

Barontini, R., \& Caprio, L. (2006). The effect of family control on firm value and performance: Evidence from continental Europe. European Financial Management, 12(5), 689-723. doi:10.1111/j.1468036x.2006.00273.x

Basu, S. (1997). The conservatism principle and the asymmetric timeliness of earnings. Journal of Accounting and Economics, 24(1), 3-37. doi:10.1016/S0165-4101(97)00014-1

Bornholdt, W. (2005). Governança na empresa familiar: Implementação e prática. Porto Alegre, RS: Bookman.

Burkart, M., Panunzi, F., \& Shleifer, A. (2003). Family firms. The Journal of Finance, 58(5), 2167-2201. doi:10.1111/1540-6261.00601

Bushman, R., Chen, Q., Engel, E., \& Smith, A. (2004). Financial accounting information, organizational complexity and corporate governance systems. Journal of Accounting and Economics, 37(2), 167-201. doi:10.1016/j.jacceco.2003.09.005

Cascino, S., Pugliese, A., Mussolino, D., \& Sansone, C. (2010). The influence of family ownership on the quality of accounting information. Family Business Review, 23(3), 246-265. doi:10.1177/0894486510374302

Chen, C.-J., Hsu, C.-Y., \& Chen, Y.-L. (2014). The impact of family control on the top management compensation mix and incentive orientation. International Review of Economics \& Finance, 32, 29-46. doi:10.1016/j. iref.2014.01.005

Chen, Q., Hou, W., Li, W., Wilson, C., \& Wu, Z. (2014). Family control, regulatory environment, and the growth of entrepreneurial firms: International evidence. Corporate Governance: An International Review, 22(2), 132-144. doi:10.1111/corg.12060

Cheng, Q. (2014). Family firm research: A review. China Journal of Accounting Research, 7(3), 149-163. doi:10.1016/j.cjar.2014.03.002

Chua, J., Chrisman, J., \& Steier, L. (2003). Extending the theoretical horizons of family business research. Entrepreneurship Theory and Practice, 27(4),331-338. doi:10.1111/1540-8520.00012 
Comitê de Pronunciamentos Contábeis. (2015). Características qualitativas da informação contábil-financeira útil. Recuperado de http://portalcfc.org.br/wordpress/wp-content/uploads/2013/o6/ cpc_pronunciamentos_2012_web.pdf

Demsetz, H. (1983). The structure of ownership and the theory of the firm. Journal of Law and Economics, 26(2), 375-390.

Donnelley, R. G. (1967). A empresa familiar. RAE-Revista de Administração de Empresas, 7(23), 161-198.

Fan, J. P. H., \& Wong, T. J. (2002). Corporate ownership structure and the informativeness of accounting earnings in East Asia. Journal of Accounting and Economics, 33(3), 401-425. doi:10.1016/S01654101(02)00047-2

Flores, J. E., Jr., \& Grisci, C. L. I. (2012). Dilemas de pais e filhos no processo sucessório de empresas familiares. Revista de Administração, 47(2), 325-337. doi:10.5700/rausp1042

Francis, J., LaFond, R., Olsson, P. M., \& Schipper, K. (2004). Costs of equity and earnings attributes. The Accounting Review, 79(4), 9671010. doi:10.2308/accr.2004.79.4.967

Freire, P. S., Soares, A. P., Nakayama, M. K., \& Spanhol, F. J. (2010). Processo de sucessão em empresa familiar: Gestão do conhecimento contornando resistências às mudanças organizacionais. Journal of Information Systems and Technology Management, 7(3), 713-736. doi:10.4301/s1807-17752010000300010

Iudícibus, S. (2005). Teoria da contabilidade (8 ed.). São Paulo, SP: Atlas.

Kazemi, H., \& Kola, B. K. D. (2015). Relationship between the advantage of timeliness and reliability of financial reporting and its impact on financial reporting quality. Journal UMP Social Sciences and Technology Management, 3(1), 78-90.

Lim, M., How, J., \& Verhoeven, P. (2014). Corporate ownership, corporate governance reform and timeliness of earnings: Malaysian evidence. Journal of Contemporary Accounting \& Economics, 10(1), 32-45. doi:10.1016/j.jcae.2013.11.001

Lopes, A. B. (2009). The relation between firm: Specific corporate governance, cross-listing and the in formativeness of accounting numbers in Brazil (Tese de doutorado em Filosofia, Faculty of Humanities, The University of Manchester).

Miller, D., Breton-Miller, I. L., Lester, R. H., \& Canella, A. A., Jr. (2007). Are family firms really superior performers? Journal of Corporate Finance, 13(5), 829-858. doi:10.1016/j.jcorpfin.2007.03.004

Miralles-Marcelo, J. L., Miralles-Quirós, M. D. M., \& Lisboa, I. (2014) The impact of family control on firm performance: Evidence from Portugal and Spain. Journal of Family Business Strategy, 5(2), 156168. doi:10.1016/j.jfbs.2014.03.002
Moura, G. D., Franz, L., \& Cunha, P. R. (2013, Agosto). Qualidade da informação contábil em empresas familiares: Influência dos níveis diferenciados de governança da BM\&FBOVESPA, tamanho e independência do conselho de administração. In $M$. A. de Vasconcellos (Coordenador geral), XVI Simpósio de Administração da Produção, Logística e Operações Internacionais. Simpósio organizado pela Fundação Getulio Vargas, Escola de Administração de Empresas de São Paulo, São Paulo, Brasil.

Peng, M. W., \& Jiang, Y. (2010). Institutions behind family ownership and control in large firms. Journal of Management Studies, 47(2), 253-273. doi:10.1111/j.1467-6486.2009.00890.x

Porta, R. La, Lopez-De-Silanes, F., \& Shleifer, A. (1999). Corporate ownership around the world. The Journal of Finance, 54(2), 471-517. doi:10.1111/0022-1082.00115

Resolução CFC No 785, de 28 de julho de 1995. Aprova a NBC T 1-Das características da informação contábil. Recuperado de http://www. cfc.org.br/sisweb/sre/docs/RES_785.doc.

Santana, A. G., \& Klann. R. C. (2016). Conservadorismo contábil e a adoção das IFRS: Evidências em empresas brasileiras familiares e não familiares. Revista Enfoque: Reflexão Contábil, 35(1), 35-53. doi:10.4025/enfoque.v35i1.29417

Shleifer, A., \& Vishny, R. W. (1997). A survey of corporate governance. The Journal of Finance, 52(2), 737-783. doi:10.1111/j.1540-6261.1997. tbo4820.x

Silva, D. T., Ayub, G. P., Pacheco, L. O., \& Macedo, M. A. S. (2012). Influência da auditoria na qualidade da informação contábil: Um estudo sob a perspectiva da relevância e da tempestividade para o ano de 2010 no Brasil. Anais do XXXVI Encontro da Anpad, Rio de Janeiro, RJ.

Silva, L. I. S., \& Brito, C. A. O. (2002). A informação contábil no ambiente globalizado. Sitientibus, (27), 179-203.

Silva, R. L. M. (2013). Adoção completa das IFRS no Brasil: Qualidade das demonstrações contábeis e o custo de capital próprio (Tese de Doutorado em Ciências Contábeis, Departamento de Contabilidade e Atuária da Faculdade de Economia, Administração e Contabilidade, Universidade de São Paulo).

Soltani, B. (2002). Timeliness of corporate and audit reports: Some empirical evidence in the French context. The International Journal of Accounting, 37(2), 215-246. doi:10.1016/So020-7063(02)00152-8

Tazik, H., \& Mohamed, Z. M. (2014). Accounting information system effectiveness, foreign ownership and timeliness of corporate financial report. 5th Asia-Pacific Business Research Conference. Kuala Lumpur, Malaysia.

Wang, D. (2006). Founding family ownership and earnings quality. Journal of Accounting Research, 44(3), 619-656. doi:10.1111/j.1475679x.2006.00213.x 